\title{
A normalização da cesárea como modo de nascer: cultura material do parto em maternidades privadas no Sudeste do Brasil
}

\section{| ${ }^{1}$ Andreza Rodrigues Nakano, ${ }^{2}$ Claudia Bonan, ${ }^{3}$ Luiz Antônio Teixeira |}

Resumo: Objetiva-se discutir o desenvolvimento de uma cultura material em torno do parto e do nascimento em um contexto de utilização maciça de inovações tecnocientíficas e explorar a hipótese da normalização da cesariana como modo de nascer, através da análise de relatos de mulheres que realizaram cesáreas em maternidades privadas do Rio de Janeiro e São Paulo. O procedimento cirúrgico é reapresentado como um modo de nascer seguro, limpo, organizado e compatível com a vida moderna, com o trabalho produtivo intenso e com os impedimentos - sociais e biológicos - de se reproduzir nos modos "antigos", figurando como um evento de continuidade, e não de exceção. Outras necessidades concorrem para a cultura material da cesariana, entre elas a gestão da vida produtiva e reprodutiva, a dimensão sócio-afetiva e o consumo. As mulheres reivindicam para si o poder sobre as escolhas feitas no processo de nascimento dos seus filhos. Vê-se produzir um novo sistema de normas e valores, mais permeável às tecnologias, modelando um novo "natural" para o parto. No contexto mais amplo da biomedicalização da vida e da reprodução, a cesariana reapresenta o parto e o nascimento na sociedade, e reivindica-se como o modo normal de dar à luz.

Palavras-chave: cesárea; parto; nascimento; normalização; setor suplementar de atenção à saúde; tecnologias.

\author{
1 Instituto Nacional de Saúde \\ da Criança, da Mulher e do \\ Adolescente Fernandes Figueira \\ / Fiocruz. Departamento de \\ Ensino. Rio de Janeiro-RJ. \\ Brasil. Endereço eletrônico: \\ andrezaenfermeira@gmail.com \\ ${ }^{2}$ Instituto Nacional de Saúde \\ da Criança, da Mulher e do \\ Adolescente Fernandes Figueira \\ / Fiocruz. Pós-Graduação em \\ Saúde da Mulher e da Criança. \\ Rio de Janeiro-RJ. Brasil. \\ Endereço eletrônico: cbonan@ \\ globo.com \\ ${ }^{3}$ Universidade Estácio de Sá \\ Pós-Graduação em Saúde da \\ Família. Rio de Janeiro-RJ, Brasil. \\ Endereço eletrônico: luiztei3@ \\ gmail.com
}

Recebido em: 08/10/2014 Aprovado em: 13/04/2015 


\section{Introdução}

As práticas de parto e nascimento no Brasil sofreram profundas mudanças desde meados do século passado, com crescente hospitalização, medicalização e mercantilização. O panorama atual da parturição demonstra uma imbricada relação de elementos de naturezas distintas: políticos, econômicos, culturais, institucionais, profissionais, entre outros. A utilização crescente da cirurgia cesariana como modo de dar à luz é emblemática da complexidade dessas transformações. Em 2012, a cesárea representou 52\% dos nascimentos ocorridos no país ( $86 \%$ no setor privado e $43 \%$ no público). Pela proporção que adquiriu - muito superior aos valores de referência de $10 \%$ a $15 \%$, preconizados pela Organização Mundial de Saúde (WHO, 1985) -, a cesárea tem sido objeto de controvérsias nos meios profissionais, políticos e acadêmicos e na sociedade civil.

$\mathrm{Na}$ última década, produziu-se um importante corpo de conhecimentos sobre a cesariana no Brasil, incluindo análises da evolução de sua frequência e das características sociodemográficas associadas (SASS; HWUANG, 2009), das diferentes práticas nos serviços públicos e privados (ALMEIDA et al., 2008), das transformações de suas indicações (HADDAD; CECCATTI, 2011) e de seus impactos nos resultados perinatais (LEAL et al., 2012). Outros estudos exploraram as motivações de mulheres e médicos para a realização da cirurgia, analisando as influências das condições de assistência ao pré-natal e ao parto, a qualidade das relações entre médicos e mulheres, os modos de organização do trabalho médico no campo da obstetrícia e aspectos psíquicos e subjetivos (medo da dor, ideias de risco para a mãe e o bebê etc) (FAÚNDES et al., 2004; CHIAVEGATTO-FILHO, 2013; MANDARINO et al., 2009).

Em um conjunto de trabalhos, a "decisão" em torno da via de parto aparece como categoria analítica central. Muitos têm como premissa (às vezes, implícita) uma dinâmica dicotômica entre escolha, preferência ou desejo da mulher, de um lado, e indicação, conveniência ou interesse do médico, de outro (DIAS et al., 2008; FAÚNDES et al., 2004; OSIS et al., 2001). Esses estudos trouxeram contribuições importantes ao revelarem, por exemplo, as disparidades entre o desejo inicial de mulheres de realizar o parto vaginal e a opção pela cesariana no final da gestação, bem como a licenciosidade nas interpretações das indicaçôes médicas para a cesariana (BARBOSA et al., 2003; FAÚNDES et al., 2004). Contudo, ao colocarem o foco analítico no plano das escolhas individuais - escolha da mulher, 
interesse do médico ou ambos -, esses estudos minimizam a complexidade do problema e pouco apreendem as transformações sociais que se co-constituem com a generalização da prática da cesariana. É importante indagar-se sobre a cultura material que se desenvolve em torno da cesárea e seus efeitos sociais e, ainda, se essa operação estaria se tornando o modo normal de nascer.

A noção de cultura material enfatiza os usos e os efeitos sociais de procedimentos técnicos e artefatos tecnológicos na construção de representações, valores e normas, nos padrões de interação, nos sistemas de produção e consumo, nas categorias de diferenciação social (classe, gênero, origem cultural e outras) e nas disposiçôes incorporadas, técnicas corporais ou a própria materialidade social do corpo (APPADURAI, 2008). Nessa perspectiva, as tecnologias e técnicas implicadas na operação cesariana podem ser interpeladas como atores em uma rede complexa de relações que envolve atores humanos e não humanos, que se influenciam, modificam e co-constituem (LATOUR, 2000; OUDSHOORN; PINCH, 2005). Qual o papel das técnicas e tecnologias (médicas e não médicas) na disposição de mulheres e médicos para realizarem cesarianas e na reorganização do ambiente, dos ritos e da economia do parto e do nascimento? Como médicos, mulheres, maternidades, seguros de saúde, mídia e outros atores participam da construção de uma cultura material específica, consumindo, modificando, domesticando e/ou reconfigurando os usos sociais dessas técnicas e das tecnologias? Como se modificam as noções de risco e segurança relacionadas à experiência de parir e nascer? Que outras normas surgem quando a cesariana se torna o modo normal de nascer?

Este artigo analisa relatos de mulheres urbanas que realizaram cesáreas em maternidades privadas. Seus objetivos são discutir o desenvolvimento de uma cultura material em torno do parto e do nascimento em um contexto de utilização maciça de inovaçooes tecnocientíficas e explorar a hipótese da normalização da cesariana como modo de nascer.

\section{Aspectos metodológicos}

Trata-se de uma pesquisa qualitativa ${ }^{1}$ que utiliza o método de estudo de relatos orais. Foram entrevistadas 33 mulheres com idade entre 18 e 35 anos, que realizaram cesárea em 2011 no setor privado de assistência à saúde na cidade do Rio de Janeiro ou São Paulo. ${ }^{2}$ Através de contato telefônico, as mulheres foram 
convidadas a participar da pesquisa; com o aceite, as entrevistas foram realizadas, em sua maioria, no domicílio das próprias mulheres. O tempo transcorrido entre o parto e a entrevista variou entre 4 e 18 meses. A pauta temática abordava a história da gestação, dos cuidados de pré-natal e do parto na última gravidez, histórico de gestações e partos anteriores, na família e no círculo de amizades e histórico afetivo-sexual e de cuidados com a saúde sexual e reprodutiva. As entrevistas foram gravadas, transcritas e posteriormente tratadas com a técnica de análise de conteúdo de modalidade temática (GOMES, 2007). Neste artigo são apresentadas algumas das categorias identificadas.

A seleção desse conjunto de entrevistas para análise é justificada pelo compartilhamento de peculiaridades entre esse grupo de mulheres - quanto aos modos de lidar com as tecnologias médicas e de se relacionar com os serviços e profissionais de saúde -, e também porque esse grupo pertence à população onde se tem encontrado maior utilização da cesárea nos nascimentos - por ter acesso ao setor de saúde suplementar e maior nível socioeconômico (CESAR et al., 2011; BARROS et al., 2011; TORRES et al., 2014).

A pesquisa observou os padrões éticos dispostos na Resolução no196/96 CONEP/CNS/MS. Assegurou-se o anonimato das participantes identificandoas com nome fictício.

\section{Resultados}

\section{Mulheres que se cuidam e planejam}

As mulheres entrevistadas têm em média 30 anos de idade, possuem, em maioria, nível superior e exercem profissões liberais. Todas vivem com companheiro e têm um ou dois filhos. Os primeiros filhos, em geral, também nasceram de cesariana.

A vida reprodutiva é projetada para quando se atinge uma situação material e profissional favorável. O planejamento da gravidez inclui a busca de cuidados específicos mesmo antes da concepção, como realizar exames para verificar suas condições de saúde e tomar ácido fólico. Elas se apresentam como mulheres que "se cuidam muito", dedicam tempo e recursos à promoção da saúde - exercícios físicos, cuidado com alimentação, ingestão de suplementos vitamínicos - e aderem a rotinas médicas de prevenção em saúde - preventivo ginecológico, ultrassonografia transvaginal, exames de sangue periódicos, visitas regulares a dentistas e dermatologistas, entre outros. Desse modo, cuidados pré- 
concepcionais e pré-natais aparecem em um contínuo com os cuidados rotineiros

com a saúde: produzir a saúde e a vitalidade com tecnologias médicas é algo bastante incorporado entre as mulheres.

Essa obstetra é a minha ginecologista de anos. Eu vou duas vezes ao ano. Faço preven-
tivo, exames. Ela passa um check-up. Eu parei de tomar a pílula três meses antes pela
indicação da obstetra e comecei a tomar o acido fólico. Ela disse que era pra preparar a
caminha do bebê [o útero]. [Enquanto isso usava preservativo] Aí quando ela liberou:
'agora pode tentar'. Aí foi logo na primeira tentativa. (Lara)

\section{A gravidez e os cuidados pré-natais}

A notícia da gravidez reorganiza as rotinas de cuidados, intensifica os encontros entre mulheres e médicos e agrega outros sentidos ao uso das técnicas e tecnologias médicas, que agora são acionadas para apoiar a geração do bebê saudável, dirimir dúvidas em relação à evolução da gestação, controlar e minimizar efeitos da gravidez no corpo da mulher.

O pré-natal é feito com ginecologistas com os quais já se tem vínculos de longa duração e nos quais se deposita confiança. As consultas de acompanhamento pré-natal acontecem pelo menos mensalmente até o início do terceiro trimestre, quando se tornam mais frequentes. Além disso, os médicos estão à disposição para contatos telefônicos ou pela internet, em caso de sintomas, eventos imprevistos ou dúvidas.

Foi no sábado que eu descobri. Aí eu liguei para a minha ginecologista e ela falou: "Então vem aqui na segunda-feira para a gente começar a fazer os exames". (Bianca)

$\mathrm{Na}$ rotina de cuidados, a realização frequente de exames laboratoriais e de imagem é imperativa. Inúmeras ultrassonografias são realizadas, tanto para acompanhamento médico do desenvolvimento fetal como para acompanhamento familiar do crescimento do "filho". Em caso de insegurança - o bebê "mexe muito" ou "mexe pouco", suspeita de "perda de líquido" -, realiza-se o exame.

Todo mês eu fazia a medição do exame de sangue. Ultra também. Por mim, eu faria toda semana, porque era muito bom. (Lara)

Outros agentes e técnicas de saúde são colocados no cenário da gravidez: nutricionistas, mudanças de hábitos alimentares e controle de peso; profissionais especializados em exercícios físicos para gestantes, procedimentos de alívio de desconfortos da gravidez, drenagem linfática e massagens; dermatologistas, cuidados cosméticos e produtos para evitar estrias. 
Eu ia uma vez por mês à consulta. Fazia exame de sangue, de urina, ultras, fazia vários exames. Aí teve uma determinada época da gravidez que ela me indicou uma nutricionista, que eu estava acima do peso. Quando eu comecei a ficar muito inchada, ela me mandou fazer drenagem linfática. (Elisa)

As tecnologias de informação e comunicação também atuam na experiência da gestação. A internet se revela um poderoso instrumento para as mulheres se informarem, monitorarem a gravidez, confirmarem a adequação dos cuidados dispensados pelos médicos e dialogarem de forma mais qualificada com eles. São consultadas páginas especializadas e realizados cadastros em sites que semanalmente fornecem informações sobre o desenvolvimento do feto.

Ganhei um livro que era sobre os cuidados, sobre a gravidez. Eu sempre lia. Hoje em dia também tem um site... que é muito fácil você baixar um aplicativo que diz, semana a semana o que está acontecendo com o seu bebê. Se você quiser saber um pouco mais você acaba entrando na internet, acaba procurando. (Paula)

\section{O parto no horizonte}

A notícia da gravidez traz imediatamente à tona a questão do parto e, especificamente, de sua via. A maioria das mulheres $(73 \%, \mathrm{n}=24)$ já havia decidido por realizar uma cesárea, mesmo antes do evento da gravidez; as demais, quase em totalidade, fizeram essa opção logo no início da gestação. É de modo simples e sem dramaticidade que narram a decisão pela cirurgia: falar de parto é, em primeira instância, falar de cesariana. A cirurgia abdominal está incorporada como uma via de parto moderna, segura e "normal". É o parto vaginal que aparece como excepcionalidade; em caso de tal escolha, teriam que ser consideradas restrições corporais, como força física, tolerância à dor, altura ou tamanho do quadril.

Desde o início, até antes mesmo da gravidez, sempre falei pra minha médica que eu ia querer cesárea. Se fosse ser uma opção minha o parto normal, a gente faria todo acompanhamento pra ver, porque eu acho que pelas minhas condições físicas eu não teria como. Porque eu tenho pouco quadril. Aquela coisa assim da família, ter esse tipo de corpo, né? (Júlia)

Desde sempre eu quis a cesariana. Porque eu acho que no auge da tecnologia do século XXI, as pessoas quererem ter filho igual a índio não rola, entendeu? Eu mesma nunca quis o parto normal, eu sempre quis cesárea. Hoje em dia é praticamente a mesma coisa, tanto normal como cesárea toma anestesia, toma tudo. A diferença é que a pessoa fica lá horas em trabalho de parto, fazendo força e tal... estou fora! A minha cirurgia começou às 10 horas e $10 \mathrm{~h} 33$ ela nasceu. (Márcia) 
Ao pensarem na cesariana, as mulheres não colocam a possibilidade de não aceitação do médico. A situação de recusa médica, de fato, não foi relatada. Em alguns casos, no início da gravidez, profissionais ponderaram que a decisão sobre o parto deveria ser tomada "mais adiante". No decorrer da gestação, vai se construindo tacitamente o acordo em torno da cirurgia. Com base em exames de imagem e outros, um quadro de riscos para o parto vaginal vai se compondo: "bebê grande", "bacia pequena", "cordão enrolado", "bebê atravessado", "pouco líquido", "muito líquido", "dificuldade de dilatação", histórias de partos difíceis na família. A litania dos riscos está presente, mesmo nos discursos das mulheres que haviam escolhido a cesárea previamente à gestação: os exames de imagem só viriam demonstrar o acerto da opção pela cirurgia.

Acho que foi no sexto ou no sétimo mês, a neném sentou e não virou mais. Ela ficou sentada na mesma posição e não virou. Aí eu tive que fazer mesmo a cesárea. A cesariana também já é tão normal que eu não me preocupei. (Lara)

Entre as mulheres, duas haviam cogitado realizar um parto vaginal e sete não haviam descartado de todo essa possibilidade no início da gravidez. Entretanto, os discursos são cheios de ambiguidades: "eu queria, se desse", "eu queria, mas sem prejudicar o bebê", "eu queria, mas o médico é que vai dizer”. Nas consultas de pré-natal, os médicos de confiança gerem essas inseguranças com discursos tranquilizadores: "vamos fazer o melhor para você e o bebê", "hoje em dia existem muitos recursos", subentendendo que recursos tecnológicos e soluções cirúrgicas estão sempre disponíveis. A frágil disposição para o "parto normal" se dissipa no curso do pré-natal; nenhuma das entrevistadas trocou de médico ou buscou alternativas movida pelo desejo de um parto vaginal.

\footnotetext{
Eu estava muito aberta entre ser normal ou cesárea. O que eu tinha pedido para ela é que eu e meu filho precisamos estar em segurança. Se você achar que é parto normal, segue normal! Se você achar que é cesárea, vamos fazer cesárea! E como de cirurgia assim eu sempre reagi muito bem - das que eu precisei fazer - então eu não era muito grilada com isso não. Eu estava com a médica que eu confiava. Eu estava muito preocupada no meu bem estar e do bebê, só isso. Quando o Miguel nasceu, que aí foi cesárea... ele estava com duas voltas no pescoço. (Isabel)
}

As visões do parto vaginal como mais doloroso, mais arriscado para bebês e mães, mais lesivo para o corpo e a sexualidade da mulher e de cesáreas salvadoras atuam de modo importante na elaboração de valores relacionados ao parto e ao nascimento. O parto denominado "normal" não parece tão normal para 

círculo de convivência. Muitas das entrevistadas também nasceram de cesarianas, havendo uma espécie de feedback geracional nessa prática.

Porque a minha mãe teve a minha irmã de parto normal. Minha irmã mais velha. Ela disse que quase morreu. Foi horrível! Tanto é que, quando eu nasci, já foi cesariana. (Lara)

O repertório das mulheres sobre o parto vaginal é repleto de imagens negativas, veiculadas também em novelas, filmes, programas de televisão, matérias de revistas e outras mídias. As histórias sobre alguém que "morreu de parto" ou um bebê que "teve problemas por causa do parto", via de regra, referem-se a um parto vaginal. Segundo algumas mulheres, a utilização da cesárea como primeira opção e não como alternativa para casos difíceis evitaria os riscos, e essas situações não chegariam a acontecer.

Sempre quis cesárea. Eu nunca quis ter parto normal; eu acho que é uma agressão muito forte. Eu não queria passar por essa experiência, eu tinha medo. Medo das dores do parto, de não conseguir ir até o final do parto, ter que fazer uma cesárea em cima da hora. Acho que a televisão traz um pouco isso pra gente, a gente fica vendo aquelas pessoas gritarem, aquelas coisas horrorosas! Então eu sempre fui muito apavorada em relação a isso. Então desde o início, até antes mesmo da gravidez, sempre falei pra minha médica que eu ia querer cesárea. (Júlia)

Contorções, espasmos, sangue, secreções, gritos e descontrole fazem parte da descrição das mulheres sobre o parto vaginal, compondo uma cenografia representada como degradante e estigmatizante para um ser humano - algo que elas não desejam como experiência de parto e nascimento.

Os temores que circundam o parto não se restringem à dor ou ao desconhecido - aqueles, passíveis de serem contornados com tecnologias analgésicas; estes, de serem conhecidos ou aprendidos em cursos pré-natais: há também o medo do incontrolável. As possibilidades do parto vaginal de escapar ao controle da mulher ou do profissional são tantas que a cesárea vai se apresentando como um parto mais adequado, passível de controle por meio de planejamento e de recursos tecnológicos.

Porque eu sempre tive muito medo do parto normal, eu tenho medo de sentir dores, ir correndo para o hospital, eu não queria isso. Inclusive eu queria um parto programado. (Míriam)

Eu já tinha tido uma cesárea antes; a primeira, porque eu não quis de jeito nenhum ter parto normal porque eu fiquei com medo. Ainda mais que meu filho ia nascer 
em dezembro. Eu queria uma coisa que fosse marcada, porque eu fiquei com medo

de nascer ou no Ano Novo, ou no Natal e ele não estar aqui. Eu mesma falei para ele que eu não queria fazer normal. Ele foi enrolando até bem perto, aí quando ele viu que eu não queria mesmo ele foi e falou: "Então tá. Então a gente vai marcar tudo direitinho”. Aí ele fez a cesárea. (Flávia)

As características associadas ao parto vaginal - doloroso, arriscado, lesivo, incontrolável e com aspectos estéticos inadequados à observação de outrem - são apresentadas pelas mulheres como algo que se deseja evitar. A cirurgia cesariana, por sua vez, é exaltada por elas. A dor da cesariana não é valorizada e dramatizada como a do parto vaginal; via de regra, "é uma dor normal", que remete a outras já conhecidas e experimentadas em procedimentos cirúrgicos - “eu já estava acostumada com aquela dor”. Predomina a percepção de que o corpo se recupera melhor e mais rápido com a cirurgia, no sentido estético, funcional e sexual, de que ela não impõe limites maiores do que o parto vaginal para retomarem suas atividades, como dirigir ou frequentar uma academia.

Porque eu só vejo pessoas que fizeram e que estão passando muito bem. É muito difícil você ver uma mulher que fala, "ah fiquei mal", muito difícil. Eu acho que alguma coisa deve ter mudado, mesmo porque o tamanho do corte mudou, já não é aquele corte enorme que faziam antigamente. Era no outro sentido da barriga, né? Agora os cortes são menores. Então assim, alguma coisa pode ter mudado sim, né? O jeito de tirar o bebê agride menos, não sei. Eu sei que a recuperação eu acho que ficou mais fácil sim. (Patrícia)

Os riscos da cesariana para a mãe e o bebê não são questionadas por mulheres e médicos em seus contatos ao longo da gestação. Entretanto, tacitamente, lidase com esses riscos buscando realizar o parto em maternidades que assegurem recursos tecnológicos avançados na eventualidade de um problema materno ou neonatal, como unidades de terapia intensiva. As tecnologias são algo em que se pode confiar e estão disponíveis para serem utilizadas.

Ela falou: "Olha, ele já está formado, com 38 já está tudo bem, já está num peso bom, e acho melhor a gente marcar porque ele teve uma queda no crescimento". E a gente marcou com 38, ele nasceu e teve que ficar em observação, mas a pediatra que fez, que acompanhou o parto falou que ele já nasceu muito cansado, que já estava desconfortável... Ele nasceu muito branquinho assim como se já estivesse ficando muito cansado de ficar na barriga. Então a gente acabou marcando na hora certa. (Clarissa)

As mulheres descrevem a cesárea como algo "comum hoje em dia", que "já é tão normal" que "não tem por que não fazer". Inclusive, é comum a utilização do verbo "operar" com o mesmo sentido de parir ou de prestar assistência 
médica ao parto. As mulheres o conjugam seja na primeira pessoa ("eu operei na maternidade X") , seja na terceira (os médicos “operam” em tais maternidades e em tais dias). A incorporação da ideia do parto como evento cirúrgico não causa estranhamento.

Ela opera lá e na $\mathrm{Y}$. E ela disse que atualmente não estava operando tanto na $\mathrm{X}$ porque ela está gostando... o Centro Cirúrgico da Y está melhor pra ela. Questôes técnicas. Bom minha médica falou assim, que a Y que é uma das melhores, senão a melhor pra ter neném, entendeu? (Júlia)

Os motivos para a realização da cirurgia transcendem as razões médicoobstétricas. A cesariana é reapresentada como algo inerente à condição "moderna”, uma "evolução", um modo normal de parir e nascer "nos dias atuais", adequado ao seu tempo, à "mulher de hoje em dia”. Em contraste, o parto vaginal é "primitivo", "coisa de antigamente", "coisa do passado".

E a gente é menos preparada mesmo para ter parto normal hoje do que era há 50 anos atrás. Fazemos muito menos esforço físico no dia a dia, então a dor de um parto normal é muito maior hoje, eu acho, do que era antigamente. Porque antigamente fica abaixada para lavar roupa, lavava roupa no rio abaixada. Então aquilo era normal, aquele movimento, aquele processo todo era normal. (Clarissa)

A cesárea é reificada pela maioria das entrevistadas como a via de parto por excelência, a mais coerente com suas trajetórias e formas de gestão da vida, do corpo e dos riscos; o modo de parir e dar à luz seus filhos que contém os valores de modernidade, controle e segurança. É nessa atmosfera que a cirurgia parece ter capturado a "magia" do nascimento e da experiência da maternidade.

No meio da gravidez eu já tinha certo fazer a cesárea. Como já tinha tido uma experiência tranquila com a cesárea, achei que devia repetir a dose. Ele [o médico] me atendeu e marcou o parto do meu filho pro domingo. Meu momento mágico já não tinha acontecido com a primeira filha... E [a cesárea] não deixou de ser mágico porque não foi normal. Então... não me senti menos mãe por não ter vivido o parto normal. (Vívian)

\section{A cesárea como modo de nascer}

As mulheres entrevistadas vivenciam a experiência da cesariana em condições específicas: contam com a participação dos companheiros, as redes familiares apoiam, participam e têm expectativas quanto ao nascimento de um novo membro, dispõem de recursos financeiros para investir em serviços como armazenamento de células-tronco e contratação de pessoal especializado para fotos ou filmagem 
do parto. A cesárea acontece segundo um roteiro planejado que confere sentidos

peculiares a essa experiência: o local e o cenário, os atores e seus papéis, a data, os percursos até a maternidade e dentro dela são definidos de antemão.

A escolha do local do nascimento, discutido e pesquisado ao longo da gestação, leva em conta elementos diferentes: disponibilidade de recursos tecnológicos de alto nível, localização conveniente, segurança, qualidade da hotelaria, oferta de serviços não médicos (filmagem, fotografia e internet, assim como serviços estéticos, como cabeleireiro e maquiador, lanchonetes e restaurantes, lojas de conveniência e outros). Estabelecimentos hospitalares que são exclusivamente maternidades são preferíveis aos serviços de obstetrícias situados em clínicas ou hospitais gerais. Espaços que "misturem" a parturiente e a criança com "gente com qualquer tipo de doença" não são a primeira escolha, e sim locais cuja "especialidade" seja atender gestantes e bebês. As maternidades asseguram ao mesmo tempo os recursos tecnológicos considerados imprescindíveis e a leveza de um "hotel" onde circulam somente "pessoas felizes com a chegada de mais um serzinho no mundo". Nesse cenário, as cesarianas não são compreendidas como uma cirurgia, e sim como um parto cuja face cirúrgica quase não se nota.

Eu vou te falar a verdade. Parece que a gente tá num hotel. Muito bom! Bom atendimento... A gente fica mais tranquila, dá uma segurança a mais. Profissional capacitado e ao mesmo tempo um lugar que não seja tanto um hospital, não tem aquela coisa: 'estou num hospital!'. Aquela carga negativa, de estar acontecendo alguma coisa. Lá só tem bebezinho nascendo, sabe? Todos os quartinhos com florzinha e todo mundo muito feliz, né? Outras pessoas, outros entes de família nascendo e tal, os familiares tão sempre com um sorrisão, todo mundo feliz, isso acho que muda um pouco o clima. (Júlia)

Pela facilidade, por hoje em dia ser uma cirurgia que não é tão assim: 'Ah, cirurgia'. Eu costumo falar que existe cirurgia e cesárea. (Paula)

$\mathrm{Na}$ quase totalidade dos casos, as cesarianas eletivas foram realizadas em data e local previamente marcados. $\mathrm{O}$ agendamento da cesárea é um arranjo técnico-social e institucional cujas vantagens são propaladas pelas mulheres. Em primeiro lugar, o arranjo é a garantia da reserva do médico, sua equipe e do lugar na maternidade. Ter plano de saúde ou condiçôes de pagar pelo parto não evita completamente problemas com a rede assistencial, e o agendamento é um modo de se proteger contra o imprevisto da falta vagas.

Eu acho que é mais fácil, tem hora marcada, local e é até mais fácil. Eu não me arrependi, porque uma amiga minha ia ter na outra semana no mesmo hospital que eu, só 
que antecipou, ela teve dois dias depois de mim. Ela foi a quatro maternidades e não conseguiu vaga, teve que pagar particular num hospital que não aceitava o plano dela porque ela não conseguiu uma vaga. O neném já estava roxo para nascer já. Como hoje em dia está todo mundo fazendo cesárea, então já está tudo agendado, a maternidade não tem vaga para quem chega na emergência. (Antônia)

O agendamento é considerado vantajoso também por favorecer outros aspectos da logística do parto. Evita-se o risco de entrar em trabalho de parto em "horários complicados" como, por exemplo, horários de trânsito congestionado, quando os deslocamentos são mais demorados, ou horários noturnos, quando mulheres e profissionais se sentem mais vulneráveis à insegurança das cidades.

Por comodidade, eu preferi ir para a maternidade X. Tanto o fluxo de trânsito, quanto a localização. Porque o local da maternidade Y não é muito seguro. Para ele [médico] era mais cômodo por causa de trânsito, de horário, de sair de casa de madrugada; é perigosa a cidade. A secretária que ligou marcou o horário e só me ligou para avisar o dia que eu ia e tudo. (Elisa)

"Marcar a cesárea" facilita a participação de companheiros, familiares e amigos, permite às mulheres organizar melhor o próprio tempo, oferecendo "facilidades", como articular atividades profissionais, domésticas e sociais. Como arranjo técnico-social, o agendamento auxilia a articulação da vida reprodutiva com lógicas de produtividade e eficiência.

Aí ela tinha feito lá as opções. A gente optou pelo dia 14 porque era o dia mais próximo do final de semana. Aí você pensa em tudo, né? A sua saída do trabalho, a sua preparação, a gente consultou o calendário, a gente fica preocupado em ter uma data de nascimento bonita, não é? O que ela aconselhou é que fosse a noite, porque a gente operava, descansava e no outro dia estaria pronta para receber visita e não corre o risco de ter gases. Então a minha operação estava marcada para as $20 \mathrm{~h}$; ela atrasou porque nesse dia ela tinha consulta. Trabalhei até mais ou menos umas $14 \mathrm{~h}$, estava com o meu BlackBerry ${ }^{\circledR}$ na verdade até na hora de eu entrar na sala de cirurgia, e ia respondendo e-mail e tal. (Isabel)

A cesárea como modo de nascer remodela o parto como evento social e íntimo. A eliminação de aspectos considerados "primitivos" e "indesejáveis" do parto vaginal, inclusive a sua dimensão sexual, a previsibilidade dos acontecimentos, garantida pelas tecnologias e rotinas técnicas, e a disponibilidade de arranjos arquitetônicos e dispositivos tecnológicos (visores plasmáticos, cine-parto, parto pela internet) são condições que confluem e contribuem para uma nova cena social do parto e do nascimento, uma espécie de intimidade ampliada e compartilhada, porosa e permeável, que borra os confins entre os âmbitos privados e públicos. 
Estava um time no quarto, né? Todo mundo foi chegando. Ele [o marido] fala assim:

"Parece que você foi ao mercado para ter o nosso filho". E assim filmou, fotografou e eu estava muito serena, quem olha parece que realmente não estava acontecendo nada. Simplesmente estão me abrindo, estão me costurando, estão tirando... (Isabel)

$\mathrm{Na}$ cultura material que se constitui em torno da prática da cesariana, destitui-se a natureza como responsável pela experiência de fazer nascer. Para liberarem seus corpos e a si mesmas da responsabilidade pela parturição, as entrevistadas contam com as equipes médicas e as tecnologias, nas quais se deposita grande confiança.

No auge da tecnologia do século XXI, não tem necessidade das pessoas terem filho como se tinha antigamente. Hoje em dia a cesárea está muito evoluída. Porque antigamente sofria, o pós-parto era doloroso, era complicado devido aos pontos, porque não deixa de ser uma cirurgia, né? E hoje em dia não tem mais isso. Eu acho que eu não sofri, o neném não sofreu, porque o neném também faz força para nascer. $\mathrm{O}$ neném também sofre com o parto normal. Foi tudo tão tranquilo, tão light que... Eu não queria correr o risco de passar horas em trabalho de parto, de ter qualquer complicação que fosse. (Márcia)

Eu acredito que um parto seguro é um parto que é bem acompanhado... que tenha médico, pediatra, o ginecologista, enfim, o anestesista, todo médico que vai ser necessário naquele momento que tenha uma segurança mesmo. [...] Eu acho que o meu foi um parto seguro. (Rose)

A terceirização do nascimento dos filhos não significa para as mulheres renúncia de protagonismo no processo de parturição. $\mathrm{O}$ entendimento de que “48 horas de trabalho de parto, não é normal” revela a constituição de um novo regime de necessidades em torno da experiência de dar à luz, cuja satisfação também depende da proatividade das mulheres. É necessário administrar a interrupção das atividades de trabalho, assegurar que a equipe médica e os recursos tecnológicos estejam ao alcance, agendar com a maternidade e contratar empresas especializadas (coleta de células tronco, filmagem), organizar a participação de familiares e amigos e, além disso, se preparar para estar "linda" e "light" no evento.

\section{Discussão}

Este artigo analisa o uso social da cesárea entre mulheres provenientes de maternidades privadas e identifica que o procedimento cirúrgico é reapresentado como um modo de nascer seguro, limpo, organizado e compatível com a vida 
moderna, com o trabalho produtivo intenso e com os impedimentos - sociais e biológicos - de se reproduzir nos modos "antigos". As práticas de cesárea devem ser entendidas de modo situado, considerando o lugar onde ocorrem, as experiências das mulheres com cuidados em saúde e com tecnologias médicas e as influências de valores sociais compartilhados (McCALLUM, 2005; McARACOUPER; JONES; SMYTHE, 2011). Neste estudo, a análise da cesárea em situação ${ }^{3}$ considera a co-constituição usuários-tecnologias; ou seja, no campo das técnicas e das tecnologias, os usuários também participam da construção de culturas materiais específicas, consumindo, modificando, domesticando ou reconfigurando os seus usos sociais (APPADURAI, 2008; OUDSHOORN; $\mathrm{PINCH}, 2005)$. Tanto as mulheres quanto a técnica cirúrgica de fazer nascer são atores na produção do cenário de normalização da cesárea.

A familiaridade das mulheres com os serviços e tecnologias médicas favorece uma interpretação biomédica dos corpos e de suas possibilidades e da vivência da cesárea como evento de continuidade, e não de exceção. A superioridade atribuída às tecnologias médicas em relação à fisiologia - no sentido de minimização de riscos, praticidade, controle da dor - e sua associação com a ideia de evolução é parte do panorama de utilização da cesárea (McCALLUM, 2005; BÉHAGUE, 2002). A incorporação simbólica e material das tecnologias na situação da cesariana atualiza as possibilidades corporais e sociais, inclusive driblando imperativos da natureza: a "cesárea marcada" transforma profundamente a experiência do parto, retirando da cena elementos como cólicas, contrações, rompimento de bolsa, espasmos, gritos e o tempo de espera, com suas expectativas, incertezas e ansiedades. A técnica cirúrgica e seus usos reapresentam o parto às mulheres.

As qualidades atribuídas à cesariana pelas mulheres estudadas (e médicos, provavelmente) se distanciam das perspectivas da saúde pública e da medicina baseada em evidências, no sentido de avaliação de riscos e benefícios ou no que diz respeito aos critérios de utilização e o papel das indicações médicas. No sentido da segurança e dos riscos, é com base em uma interpretação valorativa específica da situação que as mulheres divergem dessas vozes autorizadas: elas confiam que contam com profissionais e ambientes hospitalares de excelência e tecnologias eficazes para prevenir ou contornar eventos adversos e que têm as melhores condições possíveis de saúde, em função das rotinas de cuidados estabelecidas ao longo da vida. No segundo sentido, os usos sociais da cesariana não são 
dependentes e nem submetidos a uma necessidade medicamente determinada, uma indicação clínica ou obstétrica. Outras necessidades concorrem para a cultura material da cesariana, entre elas de gestão da vida produtiva e reprodutiva, de dimensão sócio-afetiva e de consumo. $\mathrm{O}$ agendamento da cesárea possibilita o afastamento planejado do trabalho e dos compromissos domésticos, com menor prejuízo ao desenvolvimento de tarefas e menos riscos de perda de posto. A "marcação" também permite o planejamento da participação e celebração de amigos e familiares.

O arranjo sócio-técnico do agendamento, o ambiente das maternidades privadas e um complexo mercado de serviços e tecnologias médicas e não médicas (mídia, cosmética, gastronomia) concorrem para uma nova estética e roteirização do nascimento. Numa dinâmica permanente, a cesariana assume sentidos distintos quanto mais suas possibilidades são exploradas.

As narrativas das mulheres sobre a decisão da cesárea não são de constrangimento ou imposição médica. Mesmo reconhecendo as posições diferentes de médicos e mulheres, há negociação de sentidos e acomodação de perspectivas, como já havia observado Jordan (1993). Para Beckett (2005), é preciso estar atento a usos emancipatórios da cesárea que podem ser feitos pelas mulheres. O’Dougherty (2013), estudando mulheres cariocas de classes médias, também identificou atitudes proativas na decisão da cesárea. As mulheres do presente estudo reivindicam para si o poder sobre as escolhas feitas no processo de nascimento dos seus filhos, e, em algum sentido, sentem-se privilegiadas por poderem burlar determinaçôes atribuídas à natureza de seus corpos. Nesse percurso, produz-se um novo sistema de normas e valores em torno do parto, mais permeável às tecnologias, modelando um novo "natural" para o parto, como apresenta Maffi (2013).

\section{Conclusão}

$\mathrm{Na}$ ausência de fatores clínicos que justifiquem as taxas de cesárea no Brasil, em especial no setor privado, nas últimas décadas, estudos têm sido realizados com a finalidade de descortinar essa situação (McCALLUM, 2005; BEHAGUE, 2002; HOPKINS, 2000; CARDOSO; BARBOSA, 2012). O estudo aqui apresentado vem somar-se a esses investimentos, com o olhar da co-constituição usuáriotecnologia (OUDSHOORN; PINCH, 2005). 
O grupo de entrevistadas tem um perfil diferenciado, em especial pelas vantagens socioeconômicas, que garantem o consumo de bens e serviços de naturezas diversas. As práticas desse grupo podem evocar um fenômeno referido nas publicações internacionais como too posh to push (em livre tradução, "muito chique para empurrar") (WEAVER; MAGILL-CUERDEN, 2013). A disposição das mulheres para a cesariana está em consonância com aquilo que é ofertado no mercado privado do nascimento. A infraestrutura, os recursos tecnológicos e humanos, os serviços não médicos das maternidades particulares, os modos de organização do processo de trabalho médico no setor privado, as lógicas econômicas que regem o financiamento da assistência ao nascimento, a remuneração médica e o lucro dessas empresas médicas estão voltados para esse modelo de assistência ao parto.

Enfim, entre disposições incorporadas por essas mulheres em processos de socialização - onde atuam normas de gênero, de classe, heterossexuais, biomédicas e outras - e o estilo de pensamento e práticas no mercado do nascimento, são multidimensionais os vetores que concorrem para uma cultura material do parto, onde a cirurgia cesariana tem um papel sempre mais central. As mudanças nas práticas culturais do parto não alcançam somente as mulheres de classes abastadas. Se, de modo crescente, o uso da cesárea tem sido legitimado nessas classes (MELLO-E-SOUZA, 1994), no contexto mais amplo da biomedicalização da vida e da reprodução, a cesariana reapresenta o parto e o nascimento à sociedade e reivindica-se como o modo normal de dar à luz (McARA-COUPER; JONES; SMYTHE, 2011). ${ }^{4}$

\section{Referências}

ALMEIDA, $S$ et al. Significant differences in cesarean section rates between a private and a public hospital in Brazil. Cad. Saúde Pública. Rio de Janeiro, v. 24, n. 12, p. 2909-2918, 2008. APPADURAI, A. A vida social das coisas: as mercadorias sob uma perspectiva cultural. Niterói: EDUFF, 2008.

BARBOSA, G. P et al. Parto cesáreo: quem o deseja? Em quais circunstâncias? Cad. Saúde Pública, Rio de Janeiro, v. 19, n. 6, p. 1611-1620, 2003.

BARROS, A. J. D. et al. Patterns of deliveries in a Brazilian birth cohort: almost universal cesarean sections for the better-off. Rev. Saúde Pública, São Paulo, v. 45, n. 4, p. 635-43, 2011. 
BECKETT, K. Choosing Cesarean: feminism and the politics of childbirth in the United States. Feminist Theory. London, v. 6, n. 3, p. 251-275, 2005.

BÉHAGUE, D. P. Beyond the simple economics of cesarean section birthing: women's resistance to social inequality. Culture, Medicine and Psychiatry. Netherlands, v. 26, p. 473-507, 2002.

CARDOSO, J.; BARBOSA, R. H. S. O desencontro entre desejo e realidade: a "indústria" da cesariana entre mulheres de camadas médias no Rio de Janeiro, Brasil. Physis, Rio de Janeiro, v. 22, n. 1, p. 35-52, 2012.

CESAR, J. A et al. Público versus privado: avaliando a assistência à gestação e ao parto no extremo sul do Brasil. Rev. Bras. Saúde Matern. Infant., Recife, v. 11, n. 3, p. $257-$ 263, 2011.

CHIAVEGATTO-FILHO, A. D. P. Partos cesáreos e a escolha da data de nascimento no Município de São Paulo. Ciência \& Saúde Coletiva. Rio de Janeiro, v. 18, n. 8, p. 2413$2420,2013$.

CLARKE, A.; FUJIMURA, J. What tools? Which jobs? Why right? In: . The right tools for the job: at work in Twentieth-century life sciences. New Jersey: Princeton University Press, 1992. P. 03-44.

DIAS, M. A. B et al. Trajetória das mulheres na definição pelo parto cesáreo: estudo de caso em duas unidades do sistema de saúde suplementar do estado do Rio de Janeiro. Ciência \& Saúde Coletiva, Rio de Janeiro, v. 13. n. 5, p. 1521-1534, 2008.

FAÚNDES, A et al.. Opinião de mulheres e médicos brasileiros sobre a preferência pela via de parto. Rev. Saúde Pública, São Paulo, v. 38, n. 4, p. 488-94, 2004.

GOMES, R. Análise e interpretação de dados de pesquisa qualitativa. In: MINAYO, M. C. S. (Org.). Pesquisa social: teoria, método e criatividade. Petrópolis: Vozes, 2007.

HADDAD, S. E. M.; CECATTI, J. G. Estratégias dirigidas aos profissionais para a redução das cesáreas desnecessárias no Brasil. Rev Bras Ginecol Obstet. Rio de Janeiro,v. 33, n. 5, p. 252-62, 2011.

HOPKINS, K. Are Brazilian women really choosing to deliver by c-section? Social Science \& Medicine, v.51, p.725-740, 2000.

JORDAN, B. Birth in four cultures: a crosscultural investigation of childbirth in Yucatan, Holland, Sweden, and the United States. Long Grove: Waveland Press, 1993. $4^{\circ} \mathrm{ed}$.

LATOUR, B. Ciência em ação: como seguir cientistas e engenheiros sociedade afora. São Paulo: Editora UNESp, 2000.

LEAL, M. do C. et al. Birth in Brazil: national survey into labour and birth. Reproductive Health, v.9, n.15, p. 03-08, 2012. 
MAFFI, I. Can caesarean section be "natural"? The hybrid nature of nature-culture dichotomy in mainstream obstetric culture. Tidsskrift for Forskning I Sygdom og Samfund, n. 19, p. 5-26, 2013.

MANDARINO, N. R. et al. Aspectos relacionados à escolha do tipo de parto: um estudo comparativo entre uma maternidade pública e outra privada, em São Luís, Maranhão, Brasil. Cad. Saúde Pública. Rio de Janeiro, v.25, n.7, p. 1587-1596, 2009.

McARA-COUPER, J.; JONES, M.; SMYHTE, L. Caesarean-section, my body, my choice: the construction of 'informed choice' in relation to intervention in childbirth. Feminism \& Psycology, v.22, n.1, p. 81-87, 2011.

McCALLUM, C. Explaining caesarean section in Salvador da Bahia, Brazil. Sociology of Health \& Illness, v. 27, v. 2, p. 215-242, 2005.

MELLO-E-SOUZA, C. C-sections as ideal births: the cultural constructions of beneficence and patient's rights in Brazil. Cambridge Quaterly of Healthcare Ethics. Cambridge, v.3, p. 358-366, 1994.

O'DOUGHERTY, M. Plot and irony in childbirth narratives of middle-class Brazilian women. Medical Anthopology Quaterly, v. 27, n. 1, p. 43-62, 2013.

OSIS, M. J. et al. The opinion of Brazilian women regarding vaginal labor and cesarean section. International Journal of Gynecology \& Obstetrics, v. 75, supl. 1, p. S59-S66, 2001.

OUDSHOORN, N.; PINCH, T. How users and non-users matter. In: (Org.). How users matter: the co-construction of users and technology. London: MIT Press; 2005. ROBSON, M. S. Can we reduce cesarean section rate? Best Practice \& Research Clinical Obstetrics \& Gynaecology, v. 15, n. 1, p. 179-194, 2001.

SASS, N.; HWUANG, S. M. Dados epidemiológicos, evidências e reflexões sobre a indicação de cesariana no Brasil. Diagn. Tratamento. São Paulo, v. 14, n. 4, p. 133-7, 2009.

TORRES, J. A. et al. Cesariana e resultados neonatais em hospitais privados no Brasil: estudo comparativo de dois diferentes modelos de atenção perinatal. Cad. Saúde Pública. Rio de Janeiro, v. 30, supl., p. S220-S231, 2014.

VASCONCELLOS, M. T. L. et al. Desenho da amostra Nascer no Brasil: Pesquisa Nacional sobre Parto e Nascimento. Cad. Saúde Pública, Rio de Janeiro, v.30, supl., p. S49-S58231, 2014.

WEAVER, J.; MAGILL-CUERDEN, J. "Too Posh to Push": the rise and rise of a catchphrase. BIRTH, v. 40, n. 4, p. 264-271, 2013.

WORLD HEALTH ORGANIZATION. Appropriate technology for birth. Lancet. London, v. 24, n. 2, p. 436-437, 1985. 
${ }^{1}$ A pesquisa "Itinerários Terapêuticos na definição pelo parto cesáreo" contou com financiamento CNPq através do edital no 20/2010. O artigo apresentado compóe a tese de doutorado da primeira autora. Não há conflito de interesses.

${ }^{2}$ Realizou-se estudo qualitativo, intitulado "Itinerários terapêuticos e a decisão pelo parto cesáreo", com uma amostra de mulheres proveniente do banco de dados da pesquisa "Nascer no Brasil - Inquérito Nacional sobre Parto e Nascimento" (LEAL et al., 2012; VASCONCELLOS et al., 2014). O estudo foi aprovado sob parecer CAAE-0024.0.008.000-11 junto ao Comitê de Ética em Pesquisa. Os critérios de seleção para a entrevista em profundidade foram: ter realizado cesariana entre janeiro e dezembro de 2011 em maternidades públicas, privadas ou mistas da região metropolitana do Rio de Janeiro ou da cidade de São Paulo; ter sido classificada na pesquisa quantitativa como pertencente aos grupos entre os quais se esperam taxas mais baixas de cesariana, segundo os critérios de Robson (2001), e ter entre 18 e 35 anos completos no momento do parto. Do total de entrevistas realizadas (79), este artigo analisa um conjunto de 33 do setor privado.

${ }^{3}$ Situação, no sentido empreendido por Clarke e Fujimura (1992), expressa a interação entre os diversos elementos e se aproxima da conotação de contexto; uma análise situada visa evitar que as coisas, atributos e elementos que estejam em relação sejam extraídos isoladamente, o que pode comprometer a compreensão do todo que produz a situação.

${ }^{4}$ A. R. Nakano, C. Bonan e L. A. Teixeira participaram da concepção do projeto, da análise e interpretação dos dados, redação do artigo, da revisão do conteúdo intelectual e da aprovação final da versão a ser publicada. Agradecemos a Marcos Augusto Bastos Dias pela revisão crítica do manuscrito. 


\section{Abstract}

\section{The normalization of c-section as a way of birth: material culture of birth in private hospitals in Southeastern Brazil}

The objective is to discuss the development of a material culture on labor and birth in a context of massive use of technoscientific innovations and explore the possibility of cesarean normalization as a way of being born, by analyzing reports of women who underwent cesarean in private maternity hospitals in Rio de Janeiro and Sao Paulo. The surgical procedure is resubmitted as a way to be born safe, clean, organized and compatible with modern life, with intense productive work and impediments - social and biological - to reproduce the "old" ways, appearing as an event continuity, rather than exception. Other needs contribute to the material culture of cesarean section, including the management of productive and reproductive life, socioaffective dimension and consumption. Women claim for themselves the power over the choices made in the process of birth of their children. It is seen to produce a new system of norms and values, more permeable to technologies, modeling a new "natural" for delivery. In the broader context of biomedicalization of life and reproduction, caesarean delivery represents delivery and birth in society, and it is claimed as the normal way of giving birth.

> Key words: cesarean section; childbirth; birth; standardization; supplemental health; co-construction; technologies; crop materials. 